\title{
Impact of prosthesis-patient mismatch on early and late mortality after aortic valve replacement
}

\author{
Bart M Koene ${ }^{2 *}$, Mohamed A Soliman Hamad', Wobbe Bouma ${ }^{2}$, Massimo A Mariani ${ }^{2}$, Kathinka C Peels ${ }^{3}$, \\ Jan-Melle van Dantzig ${ }^{3}$ and Albert $H$ van Straten ${ }^{1}$
}

\begin{abstract}
Background: The influence of prosthesis-patient mismatch (PPM) on survival after aortic valve replacement (AVR) remains controversial. In this study, we sought to determine the effect of PPM on early ( $\leq 30$ days) and late mortality (>30 days) after AVR or AVR combined with coronary artery bypass grafting (AVR with CABG).

Methods: Between January 1998 and March 2012, 2976 patients underwent AVR ( $n=1718)$ or AVR with CABG $(\mathrm{n}=1258)$ at a single institution. PPM was defined as an indexed effective orifice area (EOAl) $\leq 0.85 \mathrm{~cm}^{2} / \mathrm{m}^{2}$ and patients were divided into two groups based on the existence of PPM. Cumulative probability values of survival were estimated with Kaplan-Meier method and compared between groups using Breslow test. Univariate and multivariate independent predictors of early mortality were identified using logistic regression. Cox proportional-hazard regression analysis was used to determine univariate and multivariate independent predictors of late mortality.
\end{abstract}

Results: Early mortality was $6.7 \%$ in the PPM group vs $4.7 \%$ in the group with no PPM ( $p=0.013$ ). Late mortality for the PPM group at 1, 5 and 10 years was $4 \%, 16 \%$ and $43 \%$, respectively. Late mortality for the group with no PPM at 1, 5 and 10 years was 4\%, 15\% and 33\% respectively. Independent predictors of early mortality included age, severely impaired left ventricular (LV) function, endocarditis, renal dysfunction, chronic obstructive pulmonary disease (COPD) and cardiopulmonary bypass (CPB) time. Multivariate independent predictors of late mortality included age, severely impaired LV function, diabetes, peripheral vascular disease (PVD), renal dysfunction, history of a cerebrovascular accident (CVA), CPB time and a history of previous cardiac surgery. PPM was not an independent predictor of early or late mortality.

Conclusion: PPM is not an independent predictor of both early and late mortality after AVR or AVR combined with CABG.

Keywords: Prosthesis, Heart valves, Aortic valve, Replacement, Prosthesis-patient mismatch, Statistics, Survival analysis

\section{Background}

Prosthesis-patient mismatch (PPM) after aortic valve replacement (AVR) occurs when the effective orifice area (EOA) of the implanted valve prosthesis is too small compared to the body surface area (BSA) of the patient [1]. PPM is expressed by the indexed EOA (EOAI). The EOAI is calculated by dividing the

\footnotetext{
* Correspondence: b.m.j.a.koene@umcg.nl

${ }^{2}$ Department of Cardiothoracic Surgery, University Medical Center Groningen, Groningen, The Netherlands

Full list of author information is available at the end of the article
}

corresponding EOA of each valve type and size by each patient's BSA $[1,2]$.

Several studies have shown that PPM is associated with increased early or late mortality after AVR [3-6]. Other studies contradict these findings and report that PPM does not have a significant impact on survival [7-14]. Comparison of results is hampered by differences in cut-off values for EAOI. Cut-off values in literature range from $<0.6$ to $<1.1 \mathrm{~cm}^{2} / \mathrm{m}^{2}$ [15]. Comparison of results is also hampered by the fact that some authors use the published normal in vitro EOA values provided by the manufacturers to identify PPM $[2,14,16]$, while 
others use the published normal in vivo EOA values to identify PPM $[2,5,17]$.

In this study, we sought to determine the effect of PPM (cut-off value EOAI $\leq 0.85 \mathrm{~cm}^{2} / \mathrm{m}^{2}$ as described by Pibarot and colleagues [1]) on early ( $\leq 30$ days) and late ( $>30$ days) mortality after AVR or aortic valve replacement combined with coronary artery bypass grafting (AVR with CABG).

\section{Methods}

\section{Study design}

This is a retrospective observational study on consecutive patients. Data were obtained from the institutional database, normally utilized for patient care. Clinical data, echocardiographic data, catheterization data and surgical reports were entered into the institutional database prospectively and analyzed retrospectively. Because standard clinical follow-up check-ups were used and data were collected and analyzed anonymously, the need for informed consent was waived by the Medical Ethical Committee.

\section{Patients}

Between January 1998 and March 2012, 2976 patients (mean age $68 \pm 11$ years) underwent AVR $(\mathrm{n}=1718)$ or AVR with CABG $(n=1258)$ at a single institution using a mechanical or a stented biological valve prosthesis. Patients who underwent AVR with implantation of a stentless biological valve were not considered. No aortic annular enlargement procedures were performed.

Follow-up data concerning mortality were gathered using the databases of health insurance companies. The remaining data that could not be retrieved from these databases were obtained by contacting patients' general practitioners and if necessary by contacting local government authorities. Nineteen patients were lost to followup; mean follow-up was 5.7 \pm 3.7 years (range 0.0-14.7 years). Patients lost to follow-up were excluded from our analysis. Late mortality was defined as death occurring later than 30 days after surgery.

Based on the EOAI the patients were split into two groups. Patients with an EOAI $\leq 0.85 \mathrm{~cm}^{2} / \mathrm{m}^{2}$ were assigned to the group with PPM and patients with an EOAI $>0.85 \mathrm{~cm}^{2} / \mathrm{m}^{2}$ to the group without PPM.

\section{Surgical technique}

All patients underwent surgery using a standard technique. After a median sternotomy the ascending aorta and right atrium were cannulated and normothermic extracorporeal circulation with non-pulsatile flow was instituted. Myocardial protection was obtained using cold crystalloid cardioplegia (St. Thomas solution) or warm blood cardioplegia. According to surgeon's preference, cardioplegia was administered in an antegrade fashion through the aortic root and/or selectively in both coronary ostia to induce and maintain cardiac arrest. Retrograde administration of cardioplegia was not used. Concomitant myocardial revascularization was performed in 1258 patients. The distal anastomoses were performed before AVR. An overview of implanted prosthetic valve types is shown in Table 1 . No aortic annulus enlargement techniques were used.

\section{Prosthesis-patient mismatch (PPM)}

PPM was expressed by the EOAI. The EOAI was calculated by dividing the corresponding EOA of each valve type and size (registered in vitro values published by each manufacturer) by each patient's BSA $[1,2]$. PPM was defined as EOAI $\leq 0.85 \mathrm{~cm}^{2} / \mathrm{m}^{2}$ [1]. Subgroup analysis of moderate PPM (EOAI $>0.65 \mathrm{~cm}^{2} / \mathrm{m}^{2}$ and $\leq 0.85$ $\left.\mathrm{cm}^{2} / \mathrm{m}^{2}\right)(\mathrm{n}=330)$ and severe PPM (EOAI $\left.\leq 0.65 \mathrm{~cm}^{2} / \mathrm{m}^{2}\right)$ was not performed because of the small group size of patients with severe PPM $(n=14)$.

\section{Statistics}

Continuous variables were expressed as mean \pm SD. Categorical variables were expressed as percentages. Mean values were compared by using independent-samples Ttest or its non-parametric alternative, the Mann-Whitney $\mathrm{U}$ test, for continuous variables and Pearson's Chi-squared test for categorical variables.

Cumulative probability values of survival were estimated with Kaplan-Meier method and compared between groups by using Breslow test.

Logistic regression was used to identify univariate predictors and multivariate independent predictors of early mortality. Odds ratios (OR) were reported with 95\% confidence intervals (CI). Goodness of fit of the final

Table 1 Prosthetic valve distribution $(n=2957)$

\begin{tabular}{ll}
\hline Variable & Value \\
\hline $\begin{array}{l}\text { Prosthetic valve diameter (mm) } \\
\text { Median }\end{array}$ & $23 \mathrm{~mm}$ \\
Prosthetic valve type & $1476(49.9)$ \\
$\quad$ Mechanical & $899(30.4)$ \\
St. Jude Medical Standard & $442(14.9)$ \\
ATS & $93(3.1)$ \\
St. Jude Medical Regent & $42(1.4)$ \\
St. Jude Medical HP & $1487(50.1)$ \\
Biological (stented) & $146(4.9)$ \\
Carpentier-Edwards Magna & $611(20.7)$ \\
Carpentier-Edwards Perimount & $325(11.0)$ \\
Sorin Mitroflow & $134(4.5)$. \\
Medtronic Mosaic & $176(6.0)$ \\
St. Jude Medical Epic
\end{tabular}

Data are number of patients (\%). 
model was assessed with the Hosmer-Lemeshow goodness-of-fit test.

Cox proportional-hazard regression analysis was used to determine univariate predictors and multivariate independent predictors of late mortality. Hazard ratios (HR) were reported with 95\% confidence intervals $(\mathrm{CI})$.

Variables considered as potential predictors for multivariable modeling were selected by univariate analyses $(\mathrm{p}<0.05)$ and were subsequently selected by stepwise forward selection, with entry and retention in the model set at a significance level of 0.05 . Goodness of fit of the final model was assessed with the Chi-squared goodness-of-fit test.
All calculations were performed using a commercially available statistical package (SPSS 19.0; SPSS Inc, Chicago, IL). Statistically significant differences were established at $\mathrm{p}<0.05$.

\section{Results}

\section{Characteristics of the patient population}

After excluding 19 patients lost to follow-up, 2957 patients were analyzed. 1701 patients underwent AVR and 1256 patients underwent AVR with CABG. 344 patients had an EOAI $\leq 0.85 \mathrm{~cm}^{2} / \mathrm{m}^{2}$ and were allocated to the PPM group. The remaining 2613 patients with an EOAI $>0.85 \mathrm{~cm}^{2} / \mathrm{m}^{2}$ were allocated to the group without PPM. Patient characteristics are shown in Table 2. The PPM group had

Table 2 Preoperative, perioperative and postoperative data

\begin{tabular}{|c|c|c|c|}
\hline \multirow[t]{2}{*}{ Variable } & \multirow{2}{*}{$\begin{array}{l}\text { No PPM } \\
\left(\text { EOAI }>0.85 \mathrm{~cm}^{2} / \mathrm{m}^{2}\right) \mathrm{n}=2613\end{array}$} & \multirow{2}{*}{$\begin{array}{l}\text { PPM } \\
\left(\text { EOAl } \leq 0.85 \mathrm{~cm}^{2} / \mathrm{m}^{2}\right) \mathrm{n}=344\end{array}$} & \multirow[t]{2}{*}{$P$} \\
\hline & & & \\
\hline Age, years & $68 \pm 11$ & $68 \pm 11$ & 0.557 \\
\hline \multicolumn{4}{|l|}{ Sex } \\
\hline Female & $965(36.9)$ & $163(47.4)$ & $<0.001$ \\
\hline Endocarditis & $120(4.6)$ & $15(4.4)$ & 0.846 \\
\hline \multicolumn{4}{|l|}{ Preoperative LV function } \\
\hline Severely impaired & $92(3.5)$ & $11(3.2)$ & 0.759 \\
\hline Hypertension & $1125(43.1)$ & $166(48.3)$ & 0.067 \\
\hline Diabetes Mellitus & $413(15.8)$ & $96(27.9)$ & $<0.001$ \\
\hline Body weight, kg & $77 \pm 13$ & $84 \pm 15$ & $<0.001$ \\
\hline Height, cm & $170 \pm 9$ & $170 \pm 9$ & 0.807 \\
\hline Body surface area (BSA), $\mathrm{m}^{2}$ & $1.89 \pm 0.19$ & $1.95 \pm 0.18$ & $<0.001$ \\
\hline Body mass index (BMI), $\mathrm{kg} / \mathrm{m}^{2}$ & $26.8 \pm 4.0$ & $29.3 \pm 5.0$ & $<0.001$ \\
\hline Peripheral vascular disease (PVD) & $261(10.0)$ & $41(11.9)$ & 0.266 \\
\hline Renal dysfunction & $147(5.6)$ & $19(5.5)$ & 0.938 \\
\hline Chronic obstructive pulmonary disease (COPD) & $462(17.7)$ & $72(20.9)$ & 0.141 \\
\hline Cerebrovascular accident (CVA) & $122(4.7)$ & $236(6.7)$ & 0.103 \\
\hline \multicolumn{4}{|l|}{ Prosthetic valve diameter, $\mathrm{mm}$} \\
\hline Median & 23 & 23 & \\
\hline \multicolumn{4}{|l|}{ Prosthetic valve type } \\
\hline Mechanical & $1236(47.3)$ & $240(69.8)$ & $<0.001$ \\
\hline Concomitant coronary artery bypass grafting (CABG) & $1121(42.9)$ & $135(39.2)$ & 0.197 \\
\hline Cardiopulmonary bypass (CPB) time, min & $93 \pm 37$ & $99 \pm 43$ & 0.022 \\
\hline Aortic cross-clamp time, min & $68 \pm 26$ & $71 \pm 30$ & 0.077 \\
\hline Effective orifice area $(E O A), \mathrm{cm}^{2}$ & $2.14 \pm 0.44$ & $1.54 \pm 0.17$ & $<0.001$ \\
\hline Indexed effective orifice area (EOAI), $\mathrm{cm}^{2} / \mathrm{m}^{2}$ & $1.14 \pm 0.21$ & $0.79 \pm 0.06$ & $<0.001$ \\
\hline Additive EuroSCORE & $6 \pm 3$ & $6 \pm 3$ & 0.095 \\
\hline Logistic EuroSCORE & $7.66 \pm 8.14$ & $8.64 \pm 9.29$ & 0.146 \\
\hline Previous cardiac surgery & $226(8.6)$ & $59(17.2)$ & $<0.001$ \\
\hline Mean follow-up, years & $5.6 \pm 3.7$ & $6.3 \pm 4.0$ & $<0.001$ \\
\hline Mortality $\leq 30$ days & $100(3.8)$ & $23(6.7)$ & 0.013 \\
\hline
\end{tabular}

Data are mean \pm SD or percentage of patients. 
significantly more female patients ( 47.4 vs $36.9 \%, \mathrm{p}<0.001)$. The patients in the PPM group had a significantly higher average body weight $(84 \pm 15 \mathrm{~kg}$ vs $77 \pm 13 \mathrm{~kg}$, $\mathrm{p}<0.001$ ), a higher average body mass index (BMI) $\left(29.3 \pm 5.0\right.$ vs $\left.26.8 \pm 4.0 \mathrm{~kg} / \mathrm{m}^{2}, \mathrm{p}<0.001\right)$, a higher average BSA $\left(1.95 \pm 0.18\right.$ vs $\left.1.89 \pm 0.19 \mathrm{~m}^{2}, \mathrm{p}<0.001\right)$, but there was no significant difference in average height. In the PPM group significantly more mechanical valve prostheses were implanted $(69.8 \%$ vs $47.3 \%, \mathrm{p}<0.001)$, the average cardiopulmonary bypass (CPB) time was longer $(99 \pm 43$ vs $93 \pm 37 \mathrm{~min}, \mathrm{p}=0.022)$ and significantly more patients had had previous cardiac surgery $(17.2 \%$ vs $8.6 \%, \mathrm{p}<0.001)$. With regard to the distribution of comorbidities between the two groups, only the prevalence of diabetes was significantly higher in the PPM group (27.9\% vs $15.8 \%$, $\mathrm{p}<0.001)$.

\section{Early mortality}

Early mortality was $6.7 \%$ in the PPM group vs $4.7 \%$ in the other group $(\mathrm{p}=0.013)$.

The additive EuroSCORE was $6 \pm 3$ in both groups $(\mathrm{p}=0.095)$. The logistic EuroSCORE was $8.64 \pm 9.29$ in the group with PPM and $7.66 \pm 8.14$ in the group without $\operatorname{PPM}(\mathrm{p}=0.146)$.

\section{Predictors of early mortality}

Univariate predictors of early mortality (shown in Table 3) included age, severely impaired left ventricular (LV) function (ejection fraction (EF) $<30 \%$ ), endocarditis, renal dysfunction, chronic obstructive pulmonary disease (COPD), cerebrovascular accident (CVA), concomitant coronary artery bypass grafting (CABG), CPB time, aortic cross-clamp time, previous cardiac surgery and PPM.

Multivariate predictors of early mortality did not include CVA, concomitant CABG, aortic cross-clamp time, previous cardiac surgery and the existence of PPM. Multivariate predictors of early mortality were age, severely impaired LV function, endocarditis, renal dysfunction, COPD and CPB time. This well-fitting model is showing non-significance on the Hosmer-Lemeshow goodness-of-fit test $(\mathrm{p}=0.308)$.

\section{Late mortality}

Mean follow-up was $5.7 \pm 3.7$ years (range 0.0-14.7 years). Total follow-up was 16728.6 patient-years. Late mortality for the entire group at 1,5 , and 10 years was $4 \%$, $15 \%$ and $37 \%$, respectively.

Late mortality at 1,5 , and 10 years was $4 \%, 15 \%$ and $33 \%$, respectively for the group without PPM and $4 \%$, $16 \%$ and $43 \%$ for the PPM group.

\section{Predictors of late mortality}

The results of Cox regression analysis for late mortality are shown in Table 4.

Univariate analysis revealed the following predictors of late mortality: age, severely impaired LV function, diabetes, peripheral vascular disease (PVD), renal dysfunction, COPD, history of CVA, the use of a mechanical

Table 3 Univariate and multivariate analysis of early ( $\leq 30$ days) mortality

\begin{tabular}{|c|c|c|c|c|}
\hline \multirow[t]{2}{*}{ Variable } & \multicolumn{2}{|c|}{ Univariate analysis } & \multicolumn{2}{|c|}{ Multivariate analysis } \\
\hline & $P$ & OR $(95 \% \mathrm{Cl})$ & $P$ & OR $(95 \% \mathrm{Cl})$ \\
\hline Age, y & $<0.001$ & $1.04(1.02-1.06)$ & $<0.001$ & $1.04(1.02-1.07)$ \\
\hline Sex (female) & 0.058 & $1.42(0.99-2.04)$ & & \\
\hline Severely impaired LV function & 0.006 & $2.61(1.32-5.14)$ & 0.026 & $2.24(1.10-4.56)$ \\
\hline Hypertension & 0.669 & $1.08(0.75-1.56)$ & & \\
\hline Diabetes Mellitus & 0.351 & $1.24(0.79-1.94)$ & & \\
\hline Endocarditis & 0.006 & $2.38(1.28-4.44)$ & 0.006 & $2.85(1.36-5.96)$ \\
\hline Body mass index (BMI), $\mathrm{kg} / \mathrm{m}^{2}$ & 0.165 & $0.97(0.93-1.01)$ & & \\
\hline Peripheral vascular disease (PVD) & 0.052 & $1.65(0.99-2.73)$ & & \\
\hline Renal dysfunction & $<0.001$ & $2.68(1.54-4.64)$ & 0.032 & $1.90(1.06-3.40)$ \\
\hline Chronic obstructive pulmonary disease (COPD) & 0.005 & $1.78(1.19-2.68)$ & 0.029 & $1.61(1.05-2.46)$ \\
\hline Cerebrovascular accident (CVA) & 0.013 & $2.20(1.18-4.08)$ & 0.110 & $1.71(0.89-3.29)$ \\
\hline Mechanical prosthetic valve & 0.418 & $0.86(0.60-1.24)$ & & \\
\hline Concomitant coronary artery bypass grafting (CABG) & 0.004 & $1.71(1.19-2.46)$ & 0.872 & $0.96(0.62-1.51)$ \\
\hline Cardiopulmonary bypass (CPB) time, min & $<0.001$ & $1.02(1.01-1.02)$ & $<0.001$ & $1.01(1.01-1.02)$ \\
\hline Aortic cross-clamp time, min & $<0.001$ & $1.02(1.01-1.02)$ & 0.691 & $1.00(0.99-1.01)$ \\
\hline Prosthesis-patient mismatch (PPM) (cut-off $\leq 0.85 \mathrm{~cm}^{2} / \mathrm{m}^{2}$ ) & 0.014 & $1.80(1.13-2.88)$ & 0.120 & $1.50(0.90-2.48)$ \\
\hline Previous cardiac surgery & $<0.001$ & $2.96(1.90-4.59)$ & 0.072 & $1.62(0.96-2.75)$ \\
\hline
\end{tabular}

$C l=$ confidence interval; $E F=$ ejection fraction; $O R=$ Odds ratio; $L V=$ left ventricular. 
Table 4 Univariate and multivariate Cox analysis of late ( $>30$ days) mortality

\begin{tabular}{|c|c|c|c|c|}
\hline \multirow[t]{2}{*}{ Variable } & \multicolumn{2}{|c|}{ Univariate analysis } & \multicolumn{2}{|c|}{ Multivariate analysis } \\
\hline & $\bar{P}$ & HR $(95 \% \mathrm{Cl})$ & $\bar{P}$ & HR $(95 \% \mathrm{Cl})$ \\
\hline Age, years & $<0.001$ & $1.07(1.06-1.08)$ & $<0.001$ & $1.84(1.33-2.56)$ \\
\hline Sex (female) & 0.403 & $1.07(0.91-1.26)$ & & \\
\hline Severely impaired LV function & $<0.001$ & $1.93(1.40-2.67)$ & $<0.001$ & $2.24(1.10-4.56)$ \\
\hline Hypertension & 0.055 & $1.17(0.99-1.37)$ & & \\
\hline Diabetes Mellitus & $<0.001$ & $1.80(1.49-2.17)$ & 0.001 & $1.41(1.16-1.71)$ \\
\hline Endocarditis & 0.118 & $0.70(0.45-1.09)$ & & \\
\hline Body mass index (BMI), $\mathrm{kg} / \mathrm{m}^{2}$ & 0.837 & $1.00(0.98-1.02)$ & & \\
\hline Peripheral vascular disease (PVD) & $<0.001$ & $2.61(2.11-3.21)$ & $<0.001$ & $1.99(1.61-2.46)$ \\
\hline Renal dysfunction & $<0.001$ & $2.34(1.76-3.13)$ & $<0.001$ & $1.69(1.26-2.27)$ \\
\hline Chronic obstructive pulmonary disease (COPD) & $<0.001$ & $1.64(1.38-1.97)$ & $<0.001$ & $1.67(1.39-1.99)$ \\
\hline Cerebrovascular accident (CVA) & $<0.001$ & $1.88(1.40-2.53)$ & $<0.001$ & $1.71(1.27-2.31)$ \\
\hline Mechanical prosthetic valve & $<0.001$ & $0.46(0.39-0.54)$ & 0.126 & $0.85(0.70-1.05)$ \\
\hline Concomitant coronary artery bypass grafting (CABG) & $<0.001$ & $1.58(1.35-1.84)$ & 0.993 & $0.99(0.83-1.21)$ \\
\hline Cardiopulmonary bypass (CPB) time, min & $<0.001$ & $1.01(1.00-1.01)$ & 0.001 & $1.01(1.00-1.01)$ \\
\hline Aortic cross-clamp time, min & $<0.001$ & $1.01(1.00-1.01)$ & 0.385 & $1.00(0.99-1.00)$ \\
\hline Prosthesis-patient mismatch (PPM) (cut-off $\leq 0.85 \mathrm{~cm}^{2} / \mathrm{m}^{2}$ ) & 0.032 & $1.26(1.02-1.55)$ & 0.235 & $1.14(0.92-1.42)$ \\
\hline Previous cardiac surgery & $<0.001$ & $1.58(1.25-2.00)$ & 0.005 & $1.43(1.11-.84)$ \\
\hline
\end{tabular}

$\mathrm{Cl}=$ confidence interval; $\mathrm{EF}=$ ejection fraction; $\mathrm{HR}=$ hazard ratio; $\mathrm{LV}=$ left ventricular.

prosthesis, concomitant CABG, CPB time, aortic crossclamp time, previous cardiac surgery and PPM.

Multivariate analysis revealed the following independent predictors of late mortality: age, diabetes, severely impaired LV function, PVD, renal dysfunction, COPD, a history of CVA, CPB time and previous cardiac surgery. PPM was not an independent predictor of late mortality at multivariate analysis. Goodness of fit of the final model was assessed with the Chi-squared goodness-of-fit test: $\mathrm{p}<0.001$.

\section{Long-term survival after AVR or AVR with CABG}

Figure 1 displays the long-term survival after AVR or AVR with CABG stratified by PPM group. Difference in survival between the groups by Breslow test was not significant $(\mathrm{p}=0.182)$.

\section{Discussion}

The most important finding of this study is that PPM is not identified as an independent predictor of early or late mortality after AVR or AVR with CABG. Table 5 shows the independent predictors for early or late mortality after AVR or AVR with CABG. Diabetes, a history of CVA and PVD are not predictors of early mortality, but these comorbidities do have a detrimental impact on long-term survival. A history of previous cardiac surgery was an independent predictor of late mortality but not of early mortality, indicating that re-do cardiac surgery can be relatively safely performed with no significant negative effect on early survival. However most patients undergoing re-do cardiac surgery are in a more progressive phase of their disease which could explain the significant negative impact on long-term survival. Endocarditis was only a significant independent predictor of early mortality and did not have a negative effect on long-term survival. The risk-factors age, severely impaired LV function, renal dysfunction, COPD and $\mathrm{CPB}$ time were independent predictors of both early and late mortality.

The effect of PPM on early or long-term survival after AVR remains controversial [18]. Several studies have shown that PPM is a significant predictor of early or late mortality [3-6,16,19-21], whereas other studies did not report a significant association between PPM and early or late mortality [7-14,22-27]. These discrepancies may be caused by the different cut-off values for PPM (expressed in EOAI) and the different type of EOA values used to define PPM. Some authors use the projected indexed EOA derived from the published normal in vivo EOA values $[2,5,17]$, whereas others use the in vitro manufacturer's EOA $[2,14,16]$. We chose to use the in vitro EOA values provided by the manufacturers, since these values are uniform and publicly available for almost each type of prosthetic valve on the market. In our opinion, preoperative planning requires readily accessible and uniform information of all aortic valve prostheses currently available on the market. Manufacturer's EOA charts are providing this information and most 


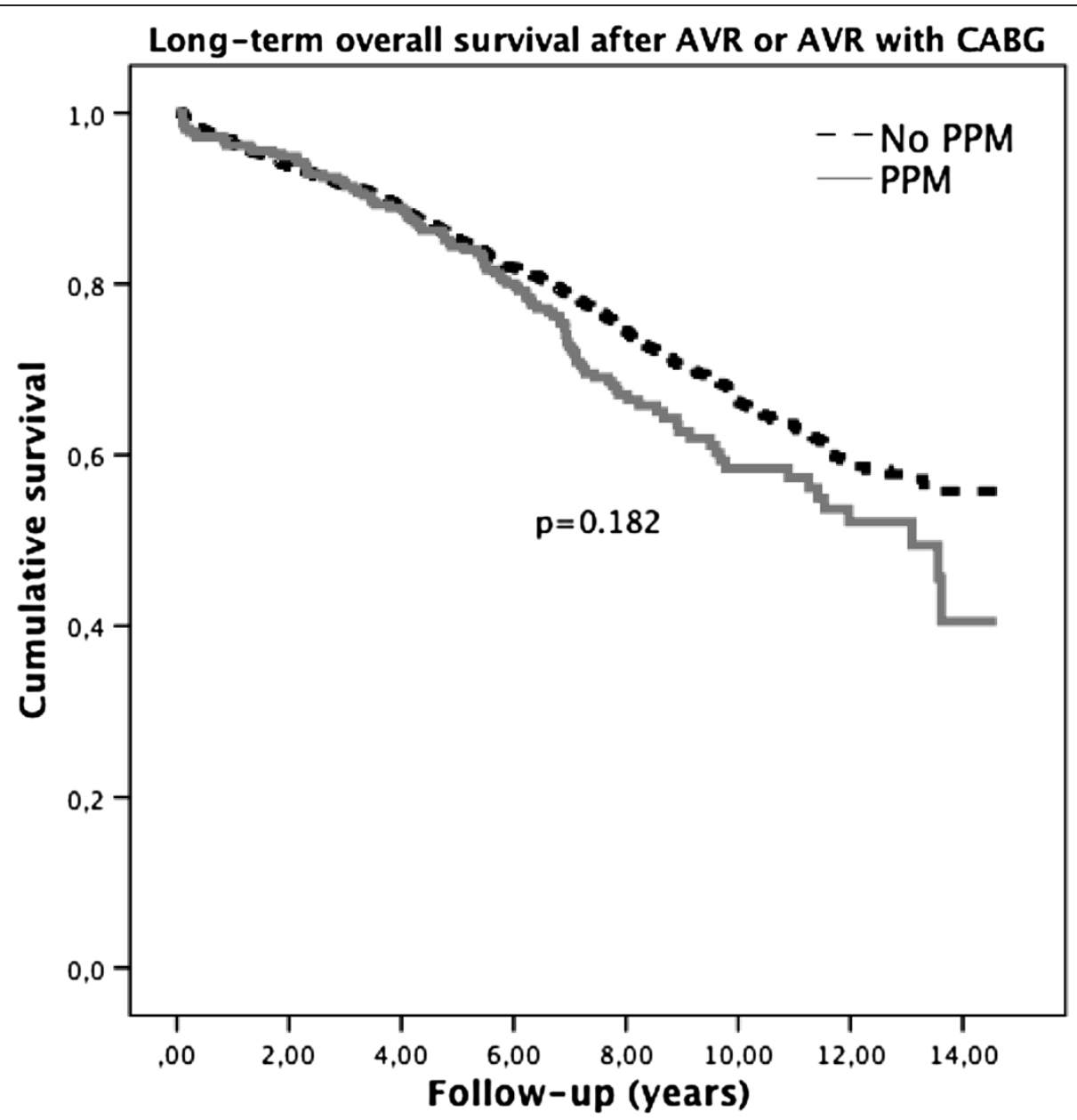

Figure 1 Overall long-term survival after AVR and AVR with CABG stratified by PPM group. The dotted line is showing long-term survival of the group without PPM and the full line is showing long-term survival of the group with PPM. There is no significant difference in survival between the two groups $(p=0.182)$.

likely the surgeon would use these values to determine the possibility of PPM.

Valve prosthesis industry is a highly competitive market. Although most contemporary biological and mechanical prosthetic valve designs have excellent hemodynamic profiles, companies want to distinguish their products with demonstrable specifications. It would be illusory to deny the existence of PPM completely, but marketing may have caused too much attention concerning this topic. Perhaps the issue of PPM is partially an industry driven hype.

An important limitation is the retrospective design of this study. Although both study populations were homogeneous for most risk-factors, some baseline patient characteristics were significantly different between the two groups. We were not able to do subgroup analyses of moderate and severe PPM due to the lack of patients with severe PPM. This can be explained by our surgical strategy to implant the biggest valve possible and to use prosthetic valves with optimal hemodynamic profiles in patients with small annular sizes,
Table 5 Multivariate independent predictors

\begin{tabular}{lcc}
\hline Variable & Early mortality & Late mortality \\
\hline Age & + & + \\
Severely impaired LV function & + & + \\
$($ EF $<30 \%)$ & & + \\
Diabetes Mellitus & - & - \\
Endocarditis & + & + \\
Peripheral vascular disease (PVD) & - & + \\
Renal dysfunction & + & + \\
Chronic obstructive pulmonary & + & + \\
disease (COPD) & & + \\
Cerebrovascular accident (CVA) & - & + \\
Cardiopulmonary bypass (CPB) time & + & + \\
Previous cardiac surgery & - & + \\
\hline
\end{tabular}

$+=$ independent predictor of early and /or late mortality.

- = no independent predictor of early and/or late mortality. 
thus inducing bias. On the other hand it illustrates that severe PPM is extremely rare when using this strategy even without using aortic annular enlargement techniques. Other studies confirm that the incidence of severe PPM is low $[22,28]$. In addition, the primary end-point was all-cause mortality. We were not able to retrieve the cause of death that might be equally important.

\section{Conclusions}

In conclusion, our findings indicate that PPM is not an independent predictor for early or late mortality after AVR or AVR with CABG. The outcome of this study puts the importance of PPM once again into perspective.

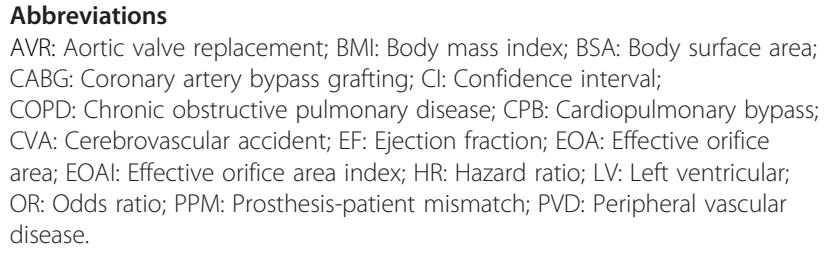

AVR: Aortic valve replacement; BMI: Body mass index; BSA: Body surface area; CABG: Coronary artery bypass grafting; $\mathrm{Cl}$ : Confidence interval;

COPD: Chronic obstructive pulmonary disease; CPB: Cardiopulmonary bypass; CVA: Cerebrovascular accident; EF: Ejection fraction; EOA: Effective orifice area; EOAl: Effective orifice area index; HR: Hazard ratio; LV: Left ventricular; OR: Odds ratio; PPM: Prosthesis-patient mismatch; PVD: Peripheral vascular disease.

\section{Competing interests}

All authors declare that they have no competing interests.

\section{Authors' contributions}

MS participated in the design of the study and helped to draft the manuscript. WB participated in the design of the study and helped to draft the manuscript. MM participated in the design of the study and revised the manuscript. KP made a substantial contribution to acquisition of data and interpretation of data. JD made a substantial contribution to acquisition of data and interpretation of data. AS made a substantial contribution to conception and design of the study, the acquisition and interpretation of data and revised the manuscript. BK made a substantial contribution to conception and design of the study, the interpretation of data, drafting the manuscript and performed the statistical analysis. All authors read and approved the final manuscript.

\section{Acknowledgements}

We thank Julienne Franssen for language-editing the manuscript.

\section{Author details}

${ }^{1}$ Department of Cardiothoracic Surgery, Catharina Hospital, Eindhoven, The Netherlands. ${ }^{2}$ Department of Cardiothoracic Surgery, University Medical Center Groningen, Groningen, The Netherlands. ${ }^{3}$ Department of Cardiology, Catharina Hospital, Eindhoven, The Netherlands.

Received: 19 February 2013 Accepted: 9 April 2013

Published: 17 April 2013

\section{References}

1. Pibarot P, Dumesnil JG: Prosthesis-patient mismatch: definition, clinical impact, and prevention. Heart 2006, 92:1022-1029.

2. Tasca G, Brunelli F, Cirillo M, DallaTomba M, Mhagna Z, Troise G, Quaini E: Impact of valve prosthesis-patient mismatch on left ventricular mass regression following aortic valve replacement. Ann Thorac Surg 2005, 79:505-510.

3. Rao V, Jamieson WR, Ivanov J, Armstrong S, David TE: Prosthesis-patient mismatch affects survival after aortic valve replacement. Circulation 2000, 102:1115-9.

4. Blais C, Dumesnil JG, Baillot R, Simard S, Doyle D, Pibarot P: Impact of valve prosthesis-patient mismatch on short-term mortality after aortic valve replacement. Circulation 2003, 108:983-988.

5. Tasca G, Mhagna Z, Perotti S, Centurini PB, Sabatini T, Amaducci A, Brunelli F, Cirillo M, Dalla Tomba M, Quaini E, et al: Impact of prosthesis-patient mismatch on cardiac events and midterm mortality after aortic valve replacement in patients with pure aortic stenosis. Circulation 2006, 113:570-576.
6. Walther T, Rastan A, Falk V, Lehmann S, Garbade J, Funkat AK, Mohr FW, Gummert JF: Patient prosthesis mismatch affects short- and long-term outcomes after aortic valve replacement. Eur J Cardiothorac Surg 2006, 30:15-19.

7. Medalion B, Blackstone EH, Lytle BW, White J, Arnold JH, Cosgrove DM: Aortic valve replacement: is valve size important? J Thorac Cardiovasc Surg 2000, 119:963-974.

8. Frapier JM, Rouviere P, Razcka F, Aymard T, Albat B, Chaptal PA: Influence of patient-prosthesis mismatch on long-term results after aortic valve replacement with a stented bioprosthesis. J Heart Valve Dis 2002, 11:543-551.

9. Flameng W, Meuris B, Herijgers P, Herregods MC: Prosthesis-patient mismatch is not clinically relevant in aortic valve replacement using the Carpentier-Edwards Perimount valve. Ann Thorac Surg 2006, 82:530-536.

10. Moon MR, Pasque MK, Munfakh NA, Melby SJ, Lawton JS, Moazami N, Codd JE, Crabtree TD, Barner HB, Damiano RJ Jr: Prosthesis-patient mismatch after aortic valve replacement: impact of age and body size on late survival. Ann Thorac Surg 2006, 81:481-488. discussion 489.

11. Monin JL, Monchi M, Kirsch ME, Petit-Eisenmann H, Baleynaud S, Chauvel C, Metz D, Adams C, Quere JP, Gueret P, Tribouilloy C: Low-gradient aortic stenosis: impact of prosthesis-patient mismatch on survival. Eur Heart $J$ 2007, 28:2620-2626.

12. Nozohoor S, Nilsson J, Luhrs C, Roijer A, Sjogren J: The influence of patient-prosthesis mismatch on in-hospital complications and early mortality after aortic valve replacement. J Heart Valve Dis 2007, 16:475-482.

13. Mascherbauer J, Rosenhek R, Fuchs C, Pernicka E, Klaar U, Scholten C, Heger M, Wollenek G, Maurer G, Baumgartner H: Moderate patient-prosthesis mismatch after valve replacement for severe aortic stenosis has no impact on short-term and long-term mortality. Heart 2008, 94:1639-1645.

14. Howell NJ, Keogh BE, Barnet V, Bonser RS, Graham TR, Rooney SJ, Wilson IC, Pagano D: Patient-prosthesis mismatch does not affect survival following aortic valve replacement. Eur J Cardiothorac Surg 2006, 30:10-14.

15. Monin JL: Prosthesis-patient mismatch: myth or reality? Heart 2009, 95:948-952.

16. Bleiziffer S, Ali A, Hettich IM, Akdere D, Laubender RP, Ruzicka D, Boehm J, Lange R, Eichinger W: Impact of the indexed effective orifice area on mid-term cardiac-related mortality after aortic valve replacement. Heart 2010, 96:865-871.

17. Mohty D, Dumesnil JG, Echahidi N, Mathieu P, Dagenais F, Voisine P, Pibarot $P$ : Impact of prosthesis-patient mismatch on long-term survival after aortic valve replacement: influence of age, obesity, and left ventricular dysfunction. J Am Coll Cardiol 2009, 53:39-47.

18. Urso S, Sadaba R, Aldamiz-Echevarria G: Is patient-prosthesis mismatch an independent risk factor for early and mid-term overall mortality in adult patients undergoing aortic valve replacement? Interact Cardiovasc Thorac Surg 2009, 9:510-518.

19. Yap CH, Mohajeri M, Yii M: Prosthesis-patient mismatch is associated with higher operative mortality following aortic valve replacement. Heart Lung Circ 2007, 16:260-264.

20. Hernandez-Vaquero D, Llosa JC, Diaz R, Khalpey Z, Morales C, Alvarez R, Lopez J, Boye F: Impact of patient-prosthesis mismatch on 30-day outcomes in young and middle-aged patients undergoing aortic valve replacement. J Cardiothorac Surg 2012, 7:46.

21. Kohsaka S, Mohan S, Virani S, Lee W, Contreras A, Reul GJ, Coulter SA: Prosthesis-patient mismatch affects long-term survival after mechanical valve replacement. J Thorac Cardiovasc Surg 2008, 135:1076-1080.

22. Howell NJ, Keogh BE, Ray D, Bonser RS, Graham TR, Mascaro J, Rooney SJ, Wilson IC, Pagano D: Patient-prosthesis mismatch in patients with aortic stenosis undergoing isolated aortic valve replacement does not affect survival. Ann Thorac Surg 2010, 89:60-64.

23. Hong S, Yi G, Youn YN, Lee S, Yoo KJ, Chang BC: Effect of the prosthesispatient mismatch on long-term clinical outcomes after isolated aortic valve replacement for aortic stenosis: a prospective observational study. J Thorac Cardiovasc Surg 2012.

24. Jamieson WR, Ye J, Higgins J, Cheung A, Fradet GJ, Skarsgard P, Germann E, Chan F, Lichtenstein SV: Effect of prosthesis-patient mismatch on longterm survival with aortic valve replacement: assessment to 15 years. Ann Thorac Surg 2010, 89:51-58. discussion 59.

25. Cotoni DA, Palac RT, Dacey LJ, O'Rourke DJ: Defining patient-prosthesis mismatch and its effect on survival in patients with impaired ejection fraction. Ann Thorac Surg 2011, 91:692-699. 
26. Urso S, Sadaba R, Monleon-Getino T, Aldamiz-Echevarria G: [Moderate patientprosthesis mismatch has no independent effect on 30-day mortality after isolated aortic valve replacement]. Rev Esp Cardiol 2010, 63:409-414.

27. Kato Y, Suehiro S, Shibata T, Sasaki Y, Hirai H: Impact of valve prosthesispatient mismatch on long-term survival and left ventricular mass regression after aortic valve replacement for aortic stenosis. J Card Surg 2007, 22:314-319.

28. Vicchio M, Della Corte A, De Santo LS, De Feo M, Caianiello G, Scardone M, Cotrufo M: Prosthesis-patient mismatch in the elderly: survival, ventricular mass regression, and quality of life. Ann Thorac Surg 2008, 86:1791-1797.

doi:10.1186/1749-8090-8-96

Cite this article as: Koene et al: Impact of prosthesis-patient mismatch on early and late mortality after aortic valve replacement. Journal of Cardiothoracic Surgery 2013 8:96.

\section{Submit your next manuscript to BioMed Central and take full advantage of:}

- Convenient online submission

- Thorough peer review

- No space constraints or color figure charges

- Immediate publication on acceptance

- Inclusion in PubMed, CAS, Scopus and Google Scholar

- Research which is freely available for redistribution 